\title{
Comparison of Pathogenic Variation among Phakopsora pachyrhizi Isolates Collected from the United States and International Locations, and Identification of Soybean Genotypes Resistant to the U.S. Isolates
}

\author{
C. Paul, Department of Crop Sciences, University of Illinois at Urbana-Champaign, Urbana 61801; R. D. Frederick, United States Department \\ of Agriculture-Agricultural Research Service (USDA-ARS) Foreign Disease-Weed Science Research Unit, Ft. Detrick, MD 21702 ; C. B. Hill, \\ Department of Crop Sciences, University of Illinois at Urbana-Champaign; and G. L. Hartman and D. R. Walker, USDA-ARS Soybean/ \\ Maize Germplasm, Pathology and Genetics Research Unit, and Department of Crop Sciences, University of Illinois at Urbana-Champaign
}

\begin{abstract}
Paul, C., Frederick, R. D., Hill, C. B., Hartman, G. L., and Walker, D. R. 2015. Comparison of pathogenic variation among Phakopsora pachyrhizi isolates collected from the United States and international locations, and identification of soybean genotypes resistant to the U.S. isolates. Plant Dis. 99:1059-1069.

A major constraint in breeding for resistance to soybean rust has been the virulence diversity in Phakopsora pachyrhizi populations. In greenhouse experiments, reactions of 18 soybean genotypes to 24 U.S. isolates from 2007 and 2008 and 4 foreign isolates were compared. Reactions of four differentials (Rppl to Rpp4) to these U.S. isolates were also compared with reactions to nine foreign isolates and three U.S. isolates from 2004. Principal component analysis (PCA) of the reaction types grouped the U.S. isolates into a single virulence group, whereas each of the foreign isolates had a unique virulence pattern. In another experiment, reactions of 11 differentials to the

24 U.S. isolates were compared and significant interactions $(P<0.001)$ were found between the isolates and host genotypes for rust severity and uredinia densities. PCA of these two measures of disease placed the 24 isolates into seven or six aggressiveness groups, respectively. In a third experiment, evaluation of 20 soybean genotypes for resistance to the previously established aggressive groups identified 10 genotypes resistant to isolates representing most of the groups. This study confirmed the pathogenic diversity in $P$. pachyrhizi populations and identified soybean germplasm with resistance to representative U.S. isolates that can be used in breeding.
\end{abstract}

Soybean rust (SBR), caused by Phakopsora pachyrhizi Syd., is one of the most destructive foliar diseases of soybean. It originated in eastern Asia and has gradually spread to soybean production areas throughout the world, including the continental United States, where it was first observed in late 2004 (9,42). SBR was found in 19 states in 2007 and in 16 states in 2008 and 2009 (http://sbr.ipmpipe.org/cgi-bin/sbr/ public.cgi), and has been observed on kudzu (Pueraria montana) as

Corresponding author: D. Walker; E-mail: david.walker@ars.usda.gov or walkerdr@illinois.edu

The use of trade, firm, or corporation names in this article is for the information and convenience of the reader. Such use does not constitute an official endorsement of approval by the United States Department of Agriculture (USDA) Agricultural Research Service, NAL, or BIC of any product or service to the exclusion of others that may be suitable.

The USDA prohibits discrimination in all its programs and activities on the basis of race, color, national origin, age, disability, and where applicable, sex, marital status, familial status, parental status, religion, sexual orientation, genetic information, political beliefs, reprisal, or because all or a part of an individual's income is derived from any public assistance program. (Not all prohibited bases apply to all programs.) Persons with disabilities who require alternative means for communication of program information (Braille, large print, audiotape, etc.) should contact USDA's TARGET Center at (202) 720-2600 (voice and TDD). To file a complaint of discrimination, write to USDA, Director, Office of Civil Rights, 1400 Independence Avenue, SW, Washington, DC 20250-9410 or call (800) 795-3272 (voice) or (202) 7206382 (TDD). USDA is an equal opportunity provider and employer.

Accepted for publication 8 January 2015.

http://dx.doi.org/10.1094/PDIS-09-14-0989-RE

This article is in the public domain and not copyrightable. It may be freely reprinted with customary crediting of the source. The American Phytopathological Society, 2015. far north as Illinois (8). Heavy infections have caused seed yield losses of 30 to $80 \%$ in southern Africa $(24,28)$ and in South America (57), and $43 \%$ in the southern United States (45). None of the soybean cultivars currently grown in the United States are reported to be resistant to SBR; therefore, destructive epidemics could result if inoculum spread and weather conditions were conducive to disease development $(5,32,57)$. Although SBR can be managed with fungicides, it requires diligent scouting and timely chemical applications when weather conditions are favorable for spraying, and it increases production input costs $(18,30)$. For example, the cost of controlling SBR in Brazil in 2003 was estimated to be U.S.\$544 million (57). Widespread use of fungicides to manage SBR also increases the environmental impact of soybean production and puts selection pressure on pathogen populations to evolve tolerance to widely used chemistries $(17,18)$. Therefore, SBR-resistant cultivars could be useful for reducing soybean yield losses and production costs in areas where rust occurs, but they must have genes that are likely to be effective in the specific geographic regions where the cultivars are to be grown.

Deployment of resistant soybean cultivars has been hampered by considerable geographical and temporal pathogenic variation among Phakopsora pachyrhizi populations $(8,39,47,55)$. Although germplasm lines with SBR resistance have been released in the Unites States $(3,15)$, resistant cultivars have yet to be marketed in North America. Although P. pachyrhizi has no known sexual stage (35), virulence diversity exists in and among field populations $(47,48,52,54,55)$, and is likely to continue to evolve through mechanisms such as somatic hybridization resulting from germ tube and hyphal anastomosis during asexual reproduction $(11,51)$. Yeh (56) found three races among 50 Taiwanese $P$. pachyrhizi uredinial isolates based upon rust reaction patterns on differentials, while Twizeyimana et al. (50) observed a high degree of genetic variation within $P$. pachyrhizi populations in Nigeria.

Dominant genes conditioning soybean resistance to $P$. pachyrhizi (Rpp genes) have been reported at six independent loci, with more than one 
alternative resistance allele at some loci $(10,12,16,19-22,25,29,31,40,46)$. Although some soybean accessions exhibit an immune (IM) or type 0 reaction to specific $P$. pachyrhizi isolates, resistance is more often characterized by the development of reddish-brown (RB) lesions with few uredinia and little or no sporulation. Susceptible (TAN) reactions are typically tan in color, at least partly due to the abundance of beigecolored urediniospores on the abaxial side of infected leaves (10). The efficacy of each Rpp gene varies among locations, years, and continents $(34,37,52,53)$. Miles et al. (33) identified 805 soybean plant introductions (PIs) from the United States Department of Agriculture-Agricultural Research Service (USDA-ARS) Soybean Germplasm Collection that were resistant to a mix of four foreign $P$. pachyrhizi isolates in greenhouse seedling assays. However, only 16 of 530 of these PIs that were screened in the field in Paraguay were resistant (34), and only 64 of the accessions were resistant to SBR in the southern United States between 2006 and 2008 (52). Kudzu accessions from northern Florida also exhibited different levels of resistance to a $P$. pachyrhizi isolate (23).

Greater knowledge about $P$. pachyrhizi virulence diversity is needed to guide the development of soybean cultivars with broad and durable resistance that is likely to be effective in the management of SBR in the United States. Such information would be useful in screening early-generation breeding lines for resistance against a range of pathogen genotypes reflecting the genetic diversity of the $P$. pachyrhizi field population in a given region. The objectives of the present study were to (i) assess the virulence and aggressiveness of 24 purified U.S. isolates collected in 2007 and 2008 on a set of differential soybean genotypes, (ii) compare the virulence of the U.S. isolates with that of a sample of foreign isolates, and (iii) evaluate 20 additional soybean genotypes for resistance to the U.S. isolates to identify genotypes with potentially novel resistance genes.

\section{Materials and Methods}

Soybean genotypes. The 31 soybean genotypes in Table 1 or subsets of those were used in a series of assays. In the first experiment, the 31 lines were challenged with the 24 U.S. P. pachyrhizi isolates listed in the upper part of Table 2. Eleven soybean lines were selected to serve as a differential panel, including PI 200492 (Rppl), PI 230970 (Rpp2), PI 462312 (Rpp3), PI 459025B (Rpp4), PI 471904 (resistance allele at the Rpp5 locus), PI 200526 (resistance allele at the Rpp5 locus), PI 594538A (Rpp1-b), PI 587880A (resistance gene in the Rpp1 region), and PI 567102B (Rpp6). The Rpp5 alleles in PI 200526 and PI 471904 exhibit different degrees of dominance, and are likely to be different genes (16). Of the other two differentials, UG-5 is an SBR-resistant line from Uganda (24), which was also found to be resistant to some U.S. isolates (36). The SBR resistance genes in UG-5 have not yet been reported. 'Williams 82' (2) was included as a susceptible check because it has consistently produced TAN lesions to all U.S. and foreign $P$. pachyrhizi isolates. Of the 20 remaining genotypes, 12 were selected because they had SBR severities $<0.2 \%$ and $\mathrm{RB}$ reactions with low sporulation in field trials conducted in Paraguay (34). 'DT 2000', a cultivar from Vietnam, and PI 423972 were included because they had developed RB reactions to U.S. isolates collected in 2004 and to several foreign isolates (39). PI 203398, PI 224268, PI 417089A, PI 567039A, PI 567041A, and PI 567046A, which were resistant to six purified domestic isolates in detached-leaf assays conducted by Paul and Hartman (36), were also included.

Table 1. Soybean genotypes inoculated with Phakopsora pachyrhizi isolates used in this study

\begin{tabular}{|c|c|c|c|c|}
\hline Genotype $^{\mathrm{a}}$ & Geographic origin ${ }^{b}$ & $\mathbf{M G}^{\mathbf{c}}$ & Resistance genes & Reference \\
\hline PI $200492[D]^{d}$ & Japan & VII & Rpp1 & 10,21 \\
\hline PI 594538A [D] ${ }^{\mathrm{d}}$ & China & VIII & Rpp1-b & 12 \\
\hline PI 587880A & China & VI & Unique allele at $R p p 1$ & 40 \\
\hline PI $230970[\mathrm{D}]^{\mathrm{d}}$ & Japan & VII & $R p p 2$ & 31,46 \\
\hline PI $462312[D]^{\mathrm{d}}$ & India & VIII & Rpp3 & 20,22 \\
\hline PI $459025 B[D]^{d}$ & China & VIII & Rpp4 & 19,46 \\
\hline PI 200526 & Japan & VIII & Rpp5 allele & 16 \\
\hline PI 471904 & Indonesia & IX & Rpp5 allele & 16 \\
\hline PI 567102B [D $]^{\mathrm{d}}$ & Indonesia & IX & Rpp6 & 29 \\
\hline UG-5 $[D]^{\mathrm{d}}$ & Uganda & VI & $R p p 1, R p p 3^{\mathrm{e}}$ & Unpublished \\
\hline DT 2000 & AVRDC, Taiwan & VI & Unknown & 39 \\
\hline PI $203398^{d}$ & Brazil & VIII & Unknown & 36 \\
\hline PI $224268^{d}$ & Japan & VIII & Unknown & 36 \\
\hline PI 398288 & Korea & $\mathrm{V}$ & Unknown & 33 \\
\hline PI $417089 A^{d}$ & Indonesia & VIII & Unknown & 36 \\
\hline PI $423972^{d}$ & Japan & IX & Unknown & 39 \\
\hline PI 506863 & Japan & IV & Unknown & 33 \\
\hline PI 507305 & Japan & $\mathrm{V}$ & Unknown & 33 \\
\hline PI 567039A & Japan & IX & Unknown & 36 \\
\hline PI $567041 \mathrm{~A}$ & Indonesia & VIII & Unknown & 36 \\
\hline PI $567046 A^{d}$ & Indonesia & VIII & Unknown & 36 \\
\hline PI $567104 B^{d}$ & Indonesia & IX & Unknown & 33 \\
\hline PI $567341^{\mathrm{d}}$ & China & IV & Unknown & 33 \\
\hline PI $567351 B^{d}$ & China & III & Unknown & 33 \\
\hline PI $587880 B$ & China & VI & Unknown & 33 \\
\hline PI 587886 & China & VI & Unknown & 33 \\
\hline PI $587905^{\mathrm{d}}$ & China & VII & Unknown & 33 \\
\hline PI 605779E & Vietnam & VIII & Unknown & 33 \\
\hline PI 605833 & Vietnam & IX & Unknown & 33 \\
\hline PI $605891 A^{d}$ & Vietnam & $\mathrm{V}$ & Unknown & 33 \\
\hline Williams $82[\mathrm{D}]^{\mathrm{d}}$ & Illinois, United States & III & Susceptible & 33 \\
\hline
\end{tabular}

a All genotypes were used in the U.S. isolate assays conducted in Urbana, IL. The first 10 genotypes and the susceptible check Williams 82 comprised a differential set.

b AVRDC = Asian Vegetable Research Development Center, Taiwan.

${ }^{\mathrm{c}} \mathrm{MG}=$ maturity group, based on information from the Germplasm Resources Information Network.

d In all, 18 genotypes, including eight differentials (indicated with a "D" in brackets), were used in the foreign isolate assays conducted in Fort Detrick, MD.

e Unpublished data indicate that UG-5 has resistance genes at the Rpp1 and Rpp3 loci. 
U.S. isolate assay. The first 24 U.S. isolates listed in Table 2 originated from single pustules on soybean or kudzu leaves collected from fields in the southern United States in 2007 and 2008, as previously described (36). These isolates had been purified through three cycles of uredinia transfers from a single spore isolated from uredinia, after which each isolate was considered to be clonal and genetically homogeneous. Isolates were increased on detached leaves of Williams 82 cultured in sealed petri dishes to obtain sufficient quantities of inoculum.

Three seeds of each of the 31 soybean genotypes were planted per pot in 32-pot trays $(52$ by $27 \mathrm{~cm}$ ) filled with soil-less Sunshine LC1 Mix (Sun Grow Horticulture Inc., Belleview, WA). Each pot was fertilized at planting with 10 to 20 Osmocote 14-14-14 pellets (ScottsSierra Horticultural Products Co., Marysville, $\mathrm{OH}$ ), and the seedlings were grown in a greenhouse with maximum daytime temperatures of
24 to $30^{\circ} \mathrm{C}$ and a 12 -h photoperiod. After 3 weeks, the seedlings were thinned to two plants per pot. Assays were arranged in a randomized complete block design with three blocks, and the experimental units were individual pots containing two plants. Each flat was a complete block containing one experimental unit of each of the 31 soybean genotypes.

Approximately 3 weeks after planting, when most seedlings were at the first fully expanded trifoliolate leaf stage (V2), plants in each flat were inoculated with a single $P$. pachyrhizi isolate. Inoculum of each isolate was prepared by suspending urediniospores in a solution of $0.01 \%$ Tween $20(\mathrm{vol} / \mathrm{vol})$ in sterile distilled water, mixing the suspension vigorously, and filtering it through a $53-\mu \mathrm{m}$ sieve. Urediniospore concentrations were adjusted using a hemacytometer to a final concentration of $4 \times 10^{4}$ urediniospores $/ \mathrm{ml}$ for inoculation $(39,50)$. The inoculation experiments were conducted in a Plant

Table 2. Reactions produced by Phakopsora pachyrhizi isolates on 11 soybean differential genotypes with rust resistance (Rpp) genes following inoculation in greenhouse assays

\begin{tabular}{|c|c|c|c|c|c|c|c|c|c|c|c|}
\hline \multirow[b]{2}{*}{ Isolates } & \multicolumn{11}{|c|}{ Differential genes $^{\mathbf{a}}$} \\
\hline & Rpp1 & $\begin{array}{c}\text { Allele at } \\
\text { Rpp1 locus }\end{array}$ & Rpp1-b & Rpp2 & Rpp3 & Rpp4 & $\operatorname{Rpp5}$ (a) & Rpp5 (b) & Rpp6 & UG-5 & Williams 82 \\
\hline \multicolumn{12}{|c|}{ U.S. $2007-2008^{b}$} \\
\hline AL07-1 & $\mathrm{RB}$ & TAN & TAN & $\mathrm{RB}$ & $\mathrm{RB}$ & TAN & $\mathrm{RB}$ & TAN & $\mathrm{RB}$ & $\mathrm{RB}$ & TAN \\
\hline AL07-2 & $\mathrm{IM}$ & TAN & TAN & $\mathrm{RB}$ & $\mathrm{RB}$ & $\mathrm{RB}$ & $\mathrm{RB}$ & TAN & HR & IM & TAN \\
\hline AL08-3 & $\mathrm{RB}$ & TAN & TAN & $\mathrm{RB}$ & RB & TAN & TAN & TAN & $\mathrm{RB}$ & $\mathrm{RB}$ & TAN \\
\hline AR08-1 & IM & TAN & TAN & $\mathrm{RB}$ & RB & TAN & $\mathrm{RB}$ & TAN & $\mathrm{RB}$ & IM & TAN \\
\hline AR08-3 & $\mathrm{RB}$ & $\mathrm{RB}$ & TAN & $\mathrm{RB}$ & $\mathrm{RB}$ & $\mathrm{RB}$ & $\mathrm{RB}$ & TAN & $\mathrm{RB}$ & $\mathrm{RB}$ & TAN \\
\hline AR08-14 & $\mathrm{RB}$ & TAN & TAN & $\mathrm{RB}$ & $\mathrm{RB}$ & TAN & $\mathrm{RB}$ & TAN & $\mathrm{RB}$ & $\mathrm{RB}$ & TAN \\
\hline FL07-1 & $\mathrm{IM}$ & TAN & TAN & $\mathrm{RB}$ & $\mathrm{RB}$ & TAN & TAN & TAN & HR & $\mathrm{IM}$ & TAN \\
\hline FL07-3 & $\mathrm{RB}$ & TAN & TAN & $\mathrm{RB}$ & $\mathrm{RB}$ & TAN & $\mathrm{RB}$ & TAN & $\mathrm{RB}$ & $\mathrm{RB}$ & TAN \\
\hline FL07-6 & $\mathrm{RB}$ & TAN & TAN & $\mathrm{RB}$ & $\mathrm{RB}$ & TAN & $\mathrm{RB}$ & TAN & HR & IM & TAN \\
\hline FL07-8 & $\mathrm{IM}$ & TAN & TAN & $\mathrm{RB}$ & $\mathrm{RB}$ & TAN & $\mathrm{RB}$ & TAN & HR & $\mathrm{IM}$ & TAN \\
\hline FL07-10 & $\mathrm{IM}$ & TAN & TAN & $\mathrm{RB}$ & $\mathrm{RB}$ & TAN & $\mathrm{RB}$ & TAN & HR & $\mathrm{IM}$ & TAN \\
\hline FL07-13 & $\mathrm{IM}$ & TAN & TAN & $\mathrm{RB}$ & $\mathrm{RB}$ & $\mathrm{RB}$ & $\mathrm{RB}$ & TAN & $\mathrm{IM}$ & $\mathrm{IM}$ & TAN \\
\hline GA08-1 & $\mathrm{RB}$ & $\mathrm{RB}$ & TAN & $\mathrm{RB}$ & $\mathrm{RB}$ & $\mathrm{RB}$ & $\mathrm{RB}$ & TAN & $\mathrm{RB}$ & $\mathrm{RB}$ & TAN \\
\hline GA08-2 & $\mathrm{RB}$ & TAN & TAN & $\mathrm{RB}$ & $\mathrm{RB}$ & TAN & $\mathrm{RB}$ & TAN & $\mathrm{RB}$ & $\mathrm{RB}$ & TAN \\
\hline IL07-1 & $\mathrm{RB}$ & TAN & TAN & $\mathrm{RB}$ & $\mathrm{RB}$ & $\mathrm{RB}$ & TAN & TAN & $\mathrm{RB}$ & $\mathrm{RB}$ & TAN \\
\hline IL08-2 & $\mathrm{RB}$ & TAN & TAN & $\mathrm{RB}$ & $\mathrm{RB}$ & $\mathrm{RB}$ & $\mathrm{RB}$ & TAN & $\mathrm{IM}$ & IM & TAN \\
\hline IL08-4 & $\mathrm{RB}$ & TAN & TAN & $\mathrm{RB}$ & $\mathrm{RB}$ & TAN & $\mathrm{RB}$ & TAN & HR & $\mathrm{RB}$ & TAN \\
\hline LA08-1 & IM & TAN & TAN & $\mathrm{RB}$ & $\mathrm{RB}$ & TAN & $\mathrm{RB}$ & TAN & HR & IM & TAN \\
\hline MS07-3 & IM & TAN & TAN & $\mathrm{RB}$ & $\mathrm{RB}$ & $\mathrm{RB}$ & $\mathrm{RB}$ & TAN & $\mathrm{IM}$ & IM & TAN \\
\hline MS07-4 & $\mathrm{RB}$ & TAN & TAN & $\mathrm{RB}$ & $\mathrm{RB}$ & TAN & $\mathrm{RB}$ & TAN & HR & IM & TAN \\
\hline OK07-1 & IM & TAN & TAN & $\mathrm{RB}$ & $\mathrm{RB}$ & TAN & $\mathrm{RB}$ & TAN & HR & IM & TAN \\
\hline TX07-1 & $\mathrm{RB}$ & TAN & TAN & $\mathrm{RB}$ & $\mathrm{RB}$ & TAN & $\mathrm{RB}$ & TAN & HR & $\mathrm{RB}$ & TAN \\
\hline TX07-6 & IM & TAN & TAN & $\mathrm{RB}$ & $\mathrm{RB}$ & TAN & $\mathrm{RB}$ & TAN & HR & IM & TAN \\
\hline TX08-1 & $\mathrm{RB}$ & TAN & TAN & $\mathrm{RB}$ & $\mathrm{RB}$ & TAN & $\mathrm{RB}$ & TAN & $\mathrm{RB}$ & IM & TAN \\
\hline \multicolumn{12}{|l|}{ U.S. 2004} \\
\hline AL04-1 ${ }^{\mathrm{c}}$ & TAN & $\ldots$ & $\ldots$ & $\mathrm{RB}$ & TAN & $\mathrm{RB}$ & $\ldots$ & $\ldots$ & $\ldots$ & $\ldots$ & TAN \\
\hline AL04-3c & TAN & $\ldots$ & $\ldots$ & $\mathrm{RB}$ & TAN & $\mathrm{RB}$ & $\ldots$ & $\ldots$ & $\ldots$ & $\ldots$ & TAN \\
\hline $\mathrm{LA} 04-1^{\mathrm{c}}$ & $\mathrm{RB}$ & $\ldots$ & $\ldots$ & $\mathrm{RB}$ & $\mathrm{RB}$ & $\mathrm{RB}$ & $\ldots$ & $\ldots$ & $\ldots$ & $\ldots$ & TAN \\
\hline \multicolumn{12}{|l|}{ Foreign $^{\mathrm{d}}$} \\
\hline $\mathrm{BZ} 01-1^{\mathrm{c}}$ & TAN & $\ldots$ & $\ldots$ & $\mathrm{RB}$ & $\mathrm{RB}$ & $\mathrm{RB}$ & $\ldots$ & $\ldots$ & $\ldots$ & $\ldots$ & TAN \\
\hline IN73-1 & IM & $\ldots$ & $\mathrm{RB}$ & $\mathrm{RB}$ & $\mathrm{RB}$ & $\mathrm{RB}$ & $\ldots$ & $\ldots$ & $\mathrm{RB}$ & IM & TAN \\
\hline PG05-1 ${ }^{\mathrm{c}}$ & TAN & $\ldots$ & $\mathrm{RB}$ & $\mathrm{RB}$ & TAN & $\mathrm{RB}$ & $\ldots$ & $\ldots$ & $\mathrm{RB}$ & $\ldots$ & TAN \\
\hline SA01-1 & TAN & $\ldots$ & $\mathrm{RB}$ & $\mathrm{RB}$ & $\mathrm{RB}$ & $\mathrm{RB}$ & $\ldots$ & $\ldots$ & $\mathrm{RB}$ & $\mathrm{RB}$ & TAN \\
\hline TH01-1 ${ }^{\mathrm{c}}$ & TAN & $\ldots$ & $\ldots$ & $\mathrm{RB}$ & TAN & $\mathrm{RB}$ & $\ldots$ & $\ldots$ & $\ldots$ & $\ldots$ & TAN \\
\hline TW72-1 & TAN & $\ldots$ & $\ldots$ & $\mathrm{RB}$ & TAN & $\mathrm{RB}$ & $\ldots$ & $\ldots$ & $\ldots$ & $\ldots$ & TAN \\
\hline TW80-2 & TAN & $\ldots$ & $\mathrm{RB}$ & $\mathrm{T}$ & TAN & $\mathrm{RB}$ & $\ldots$ & $\ldots$ & $\mathrm{RB}$ & $\mathrm{T}$ & TAN \\
\hline ZM01-1 & TAN & $\ldots$ & $\mathrm{RB}$ & $\mathrm{RB}$ & TAN & $\mathrm{RB}$ & $\ldots$ & $\ldots$ & $\mathrm{RB}$ & $\mathrm{T}$ & TAN \\
\hline NIG-05-06e & RB/Mixed & $\ldots$ & HR & RB/Mixed & $\mathrm{RB}$ & RB/Mixed & $\ldots$ & $\ldots$ & $\ldots$ & $\mathrm{RB} / \mathrm{HR}$ & $\ldots$ \\
\hline
\end{tabular}

${ }^{\text {a }} R p p 1=$ PI 200492, $R p p 1$ locus = PI 587880A, $R p p 1-b=$ PI 594538A, Rpp2 = PI 230970, Rpp3 = PI 462312, Rpp4 = PI 459025B, Rpp 5 (a) = PI 471904, Rpp5 (b) $=$ PI 200526, and $R p p 6=$ PI 567102B. Rpp 1 locus $=$ an allele that is different from $R p p 1$ gene, $R p p 1 b=$ an allele of $R p p 1$ gene or linked gene. HR $=$ hypersensitive response characterized by brown discoloration with no uredinia development, $\mathrm{RB}=$ reddish-brown reaction type, $\mathrm{T}=\mathrm{TAN}$ indicates tan-colored reaction type, IM = an immune response with no visible symptoms, MIXED = both RB and TAN reaction types present on the same leaf.

b Isolate names indicate state of origin $(\mathrm{AL}=$ Alabama, $\mathrm{AR}=$ Arkansas, $\mathrm{FL}=$ Florida, $\mathrm{IL}=$ Illinois, $\mathrm{LA}=$ Louisiana, $\mathrm{MS}=\mathrm{Mississippi}, \mathrm{GA}=\mathrm{Georgia}, \mathrm{OK}=$ Oklahoma, and TX = Texas), year of collection (2007 or 2008), and isolate number for location of collection.

${ }^{c}$ Reaction type data for differentials originally reported by Pham et al. (39).

${ }^{\mathrm{d}}$ Foreign isolate names indicate the country of origin, followed by year and location of collection. $\mathrm{BZ}=\mathrm{Brazil}, \mathrm{IN}=\mathrm{India}, \mathrm{PG}=\mathrm{Paraguay}, \mathrm{SA}=\mathrm{South} \mathrm{Africa}, \mathrm{TH}=$ Thailand, TW = Taiwan, ZM = Zimbabwe, and NIG = Nigeria .

e Reaction type data for differentials originally reported in Twizeyimana et al. (50) or Twizeyimana and Hartman (47). 
Biosafety Level 2 greenhouse at the University of Illinois in Urbana in the winter months of 2009 and 2010, under a permit from the USDA Animal and Plant Health Inspection Service (APHIS). The abaxial (lower) leaf surface of the first trifoliolate leaf on each plant was sprayed with a urediniospore suspension at a rate of $50 \mathrm{ml} / \mathrm{flat}$ using an atomizer attached to an air compressor at a pressure of $1.4 \times 10^{5} \mathrm{~Pa}$ (Paasche Airbrush Co., Taiwan). Inoculated plants were incubated in a mist chamber overnight at 20 to $22^{\circ} \mathrm{C}$. Plants were removed from the mist chamber and placed on greenhouse benches in a room maintained at 24 to $25^{\circ} \mathrm{C}$ and with a 12-h photoperiod, where they were watered daily. Two isolates were tested at a time at 2-day intervals due to limited space in the mist chamber. Urediniospore viability was determined by spraying inoculum of each isolate immediately after inoculation onto the surface of $2 \%$ water agar medium in petri dishes and then observing the percentage of germinated urediniospores after $24 \mathrm{~h}$ of incubation at room temperature in the dark using a stereoscope at $\times 100$ magnification $(5,25)$.

At 15 to 16 days after inoculation, SBR reactions and disease severity were assessed on the abaxial surface of the first trifoliolate leaf of each plant. The reaction types were recorded as (i) IM, if there were no visible lesions; (ii) RB, if there were reddish-brown lesions with either no uredinia or only a few sparsely sporulating uredinia, indicating a resistance reaction; or (iii) TAN, if there was a tan-colored reaction with abundantly sporulating uredinia, indicating a susceptible reaction (10). Leaflets that developed light-brown lesions with no uredinia were recorded as having a hypersensitive response (HR), as previously described by Jordan et al. (23) on kudzu leaves. When no lesions were observed on a trifoliolate, additional leaflets were examined to confirm the absence of lesion development. Disease severity was assessed in the greenhouse using a visual scale of 1 to 5 devised by Miles et al. (32), in which $1=$ no visible lesions, 2 = a few scattered lesions, $3=$ a moderate number of lesions on part of the leaflet, $4=$ an abundant number of lesions on part of the leaflet, and $5=$ prolific lesion development over most of the leaflet. After reaction type and rust severity were rated, two leaflets of each soybean genotype per replication were excised, placed in an envelope, and baked in an oven overnight at $50^{\circ} \mathrm{C}$ to kill the urediniospores and other fungal tissue. This was necessary to comply with the APHIS rust permit regulations for working with $P$. pachyrhizi in Illinois. The numbers of lesions and sporulating uredinia per square centimeter of leaf tissue were determined by counting the numbers within two circles, each $1 \mathrm{~cm}^{2}$ in area, on either side of the midrib on the abaxial side of each leaflet. This was done using a dissecting microscope at $\times 100$, as described by Paul et al. (38). The mean of the four circles was then calculated for each experimental unit. The average number of uredinia per lesion on each leaflet was calculated by dividing the number of sporulating uredinia per circle by the number of lesions. Genotypes with mean severity ratings $<2.5$ or with fewer than 2.0 uredinia/lesion were considered to be resistant. Inoculations with all of the isolates were repeated once, with three replications (blocks).

Foreign isolate assay. Assays were conducted with four foreign P. pachyrhizi isolates from India (IN73-1), South Africa (SA01-1), Taiwan (TW80-2), and Zimbabwe (ZM01-1) (Table 2) on a subset of 18 soybean genotypes, including eight differentials (Table 1). The differentials included accessions with the genes Rppl through $R p p 4, R p p 1-b$, and Rpp6, as well as UG-5 and the susceptible check Williams 82. Another 10 soybean genotypes (Table 1) were also included to evaluate the phenotypic reactions to the foreign isolates. These assays were arranged in a randomized complete block design with two blocks (replications). An experimental unit consisted of 1 pot with three plants of each genotype and 32 pots/tray, as previously described for the assay with the U.S. isolates. Inoculations with four isolates on 18 genotypes were made once, with two replications.

All four foreign isolates had been established from urediniospores on soybean leaves collected from the countries and years indicated by the isolate name (6). All increases were made on the susceptible soybean genotype Williams 82 in the greenhouse at the USDA-ARS Foreign Disease-Weed Science Research Unit Biological Safety Level 3 Containment Facility at Fort Detrick, MD (26). Urediniospores were collected and stored in liquid nitrogen, as previously described $(14,33)$. Prior to inoculation, frozen urediniospores were heat shocked at $40^{\circ} \mathrm{C}$ for $5 \mathrm{~min}$ and then rehydrated with sterile, distilled water by overnight incubation at $100 \%$ relative humidity in a covered petri plate at room temperature. Inoculum was prepared as previously described (6). Urediniospores were quantified using a hemacytometer and were suspended in $0.01 \%$ ( $\mathrm{vol} / \mathrm{vol})$ Tween 20 (sodium monolaurate) in distilled water. The suspension was adjusted to a final concentration of $25 \times 10^{3}$ urediniospores $/ \mathrm{ml}$ (7), and the inoculations were performed as previously described (39). Two weeks after inoculation, reaction types were recorded using the criteria of Bromfield and Hartwig (10) as TAN, RB, or IM by inspecting the abaxial side of the leaflets.

Comparison of the U.S. isolates with nine foreign isolates. Variation in virulence was also assessed by comparing the reactions that the 24 U.S. isolates from 2007 and 2008 induced on a set of four differentials (Rppl to Rpp4) with the reactions induced by nine foreign isolates and three U.S. isolates from 2004. Four of the foreign isolates and the 2004 isolates from Alabama and Louisiana had been used in one previous study (39), and the Nigerian isolate NIG05-06, that was previously reported (49), was also included to investigate isolate grouping patterns using principal component analysis (PCA) (Table 2).

Data analysis. Analysis of disease severity, number of lesions, number of uredinia, and uredinia per lesion from the assays with the 24 U.S. isolates was performed using PROC MIXED, with the analysis of variance (ANOVA) option restricted maximum likelihood (REML) (SAS version 9.3; SAS Institute Inc., Cary, NC). Soybean genotype and isolate were fixed effects and block was treated as a random effect. Least square means within each genotype-isolate combination were generated with LSMEANS statements. Data were combined from the two trials prior to analysis because error variance heterogeneity was found to be nonsignificant using ANOVA in PROC GLM with an option Hovtest $=$ levene. Least square means for severity, number of lesions, number of uredinia, and number of uredinia per lesion were estimated from these analyses for PCA. Principal component (PC) scores were calculated from the resulting data matrix of 24 observations (isolates) and 11 variates (differential genotypes), and the first two PCs were plotted to visualize isolate clustering. To assess virulence diversity between the 4 foreign and 24 U.S. isolates, reaction types on 18 genotypes were recorded for each isolate, and were then coded for the PCA as follows: IM and RB were both considered resistance reactions, and were coded as 0 , while the TAN susceptible reactions were coded as 1 . Pathotype clusters were determined for foreign and U.S. isolates using the average linkage method and clustering criteria in PROC CLUSTER and PROC TREE.

Determination of $P$. pachyrhizi isolate aggressiveness groups. Least square means for rust severity for each isolate from the REML analysis of the U.S. isolate assays were used for multivariate analysis. Prior to multivariate analysis, rust severity data for the U.S. isolates were used to delineate three severity classes using PROC UNIVARIATE in SAS (version 9.3; SAS Institute Inc.). The first, second, and third categories consisted of values that were greater than one standard deviation above the grand mean, within one standard deviation of the mean, or lower than one standard deviation below the grand mean, respectively. PCA was used to examine the multivariate structure of the $P$. pachyrhizi isolates, as described by Chakraborty et al. (13), using three severity classes (i.e., classes 1 to 3 ) for each isolate and each genotype as separate variates. PCA was conducted using the SAS procedure PRINCOMP, and the first two PCs were plotted to visualize isolate groupings. Aggressiveness groups were determined using the average linkage method and clustering criteria in PROC CLUSTER and PROC TREE. The number of isolate clusters was optimized by plotting the proportional reduction in residual sum of squares against the number of clusters (44). A similar procedure was used to examine the distribution of the uredinia density data and uredinia per lesion on leaflets, with low, medium, and high classes based on departure from the mean. Twenty soybean genotypes were evaluated for resistance to each isolate within each of the respective aggressiveness groups to identify genotypes resistant to $P$. pachyrhizi. 


\section{Results}

Infection types induced by 24 U.S. $P$. pachyrhizi isolates from 2007 and 2008. All of the U.S. isolates produced an RB reaction on PI 230970 (Rpp2) and PI 462312 (Rpp3) and a TAN reaction on PI 200526 (allele at Rpp5), PI 594538A (Rppl-b), and Williams 82 (Table 2). PI 200492 (Rppl) and UG-5 plants had an IM reaction to 45 and $60 \%$ of the isolates, respectively, and an $\mathrm{RB}$ reaction to the remaining isolates. PI 459025B (Rpp4) developed RB lesions with profusely sporulating uredinia following infection with $30 \%$ of the isolates, while other isolates induced a TAN reaction. RB lesions were induced on PI 471904 (resistance allele at the Rpp5 locus) by $88 \%$ of the isolates. PI 567102B (Rpp6) developed RB lesions when challenged by $42 \%$ of the isolates and the previously described HR type of response or IM when challenged with the rest of the isolates. Although $8 \%$ of the U.S. isolates produced RB lesions on PI 587880A, which has a unique allele at the Rppl locus (36), the rest of the isolates produced a TAN reaction.

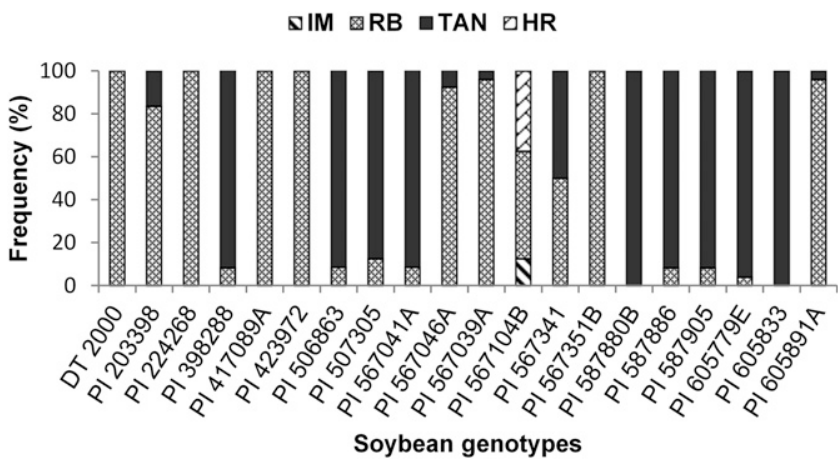

Fig. 1. Frequencies of infection types on soybean genotypes with unidentified resistance genes on plants challenged with 24 Phakopsora pachyrhizi isolates collected in the United States in 2007 or 2008. Reaction type abbreviations: $\mathrm{IM}=$ immune, $\mathrm{RB}=$ reddish-brown lesions (incomplete resistance), TAN = tan-colored reaction (susceptible), and $\mathrm{HR}=$ hypersensitive reaction with brown lesions.
The soybean genotypes with uncharacterized resistance genes differed in their reactions to the 24 U.S. isolates (Fig. 1). For example, all 24 isolates produced $\mathrm{RB}$ reactions on five soybean genotypes, but a TAN reaction on PI 587880B and PI 605833. More than $90 \%$ of the isolates induced TAN reactions on seven other host genotypes, while four genotypes developed RB lesions. RB lesions or brown lesions resembling the HR described (23) were induced on PI 567104B plants by 50 and $38 \%$ of the isolates, respectively. The remaining isolates produced an immune reaction. AL07-2, FL07-1, FL07-6, and LA08-1 were the most virulent isolates, producing a TAN reaction on 52 to $60 \%$ of the soybean genotypes (data not shown). The numbers of lesions with sporulating uredinia per square centimeter varied, however, depending on the virulence of the isolate on specific host genotypes.

Comparison of virulence between U.S. and foreign isolates. The virulence of the nine foreign isolates and the three 2004 U.S. isolates differed from that of the 2007 and 2008 U.S. isolates on some of the soybean differentials (Table 2). For instance, all of the 2007 and 2008 U.S. isolates produced either RB or IM reactions on PI 200492 (Rppl) and PI 462312 (Rpp3), whereas the two 2004 Alabama isolates and most of the foreign isolates produced TAN reactions. The one exception was an isolate from India which induced an IM reaction on the PI 200492 (Rppl) genotype. In addition, most of the U.S. isolates produced a TAN reaction on PI 459025B (Rpp4), whereas all of the foreign isolates produced an $\mathrm{RB}$ reaction, or an $\mathrm{RB} /$ mixed reaction in the case of the NIG-05-06 isolate. On PI 594538A (Rppl-b), all of the U.S. isolates produced a TAN reaction, while five of the foreign isolates produced an RB reaction and the NIG-05-06 isolate induced an HR reaction (Table 2). All U.S. isolates, including three isolates from 2004, and seven of the nine foreign isolates produced an RB reaction on PI $230970(R p p 2)$. The isolate from Taiwan produced a TAN reaction and the NIG-05-06 isolate produced an RB or mixed reaction. The 24 U.S. isolates produced $\mathrm{RB}, \mathrm{HR}$, or IM reactions on PI 567102B (Rpp6), and the five foreign isolates produced an $\mathrm{RB}$ reaction.

PCA performed on the reactions produced by the 24 U.S. isolates and the foreign isolates IN73-1, SA01-1, ZM01-1, and TW80-2 on 18 soybean genotypes revealed one primary isolate group containing all of the U.S. isolates, whereas none of the 4 foreign isolates were

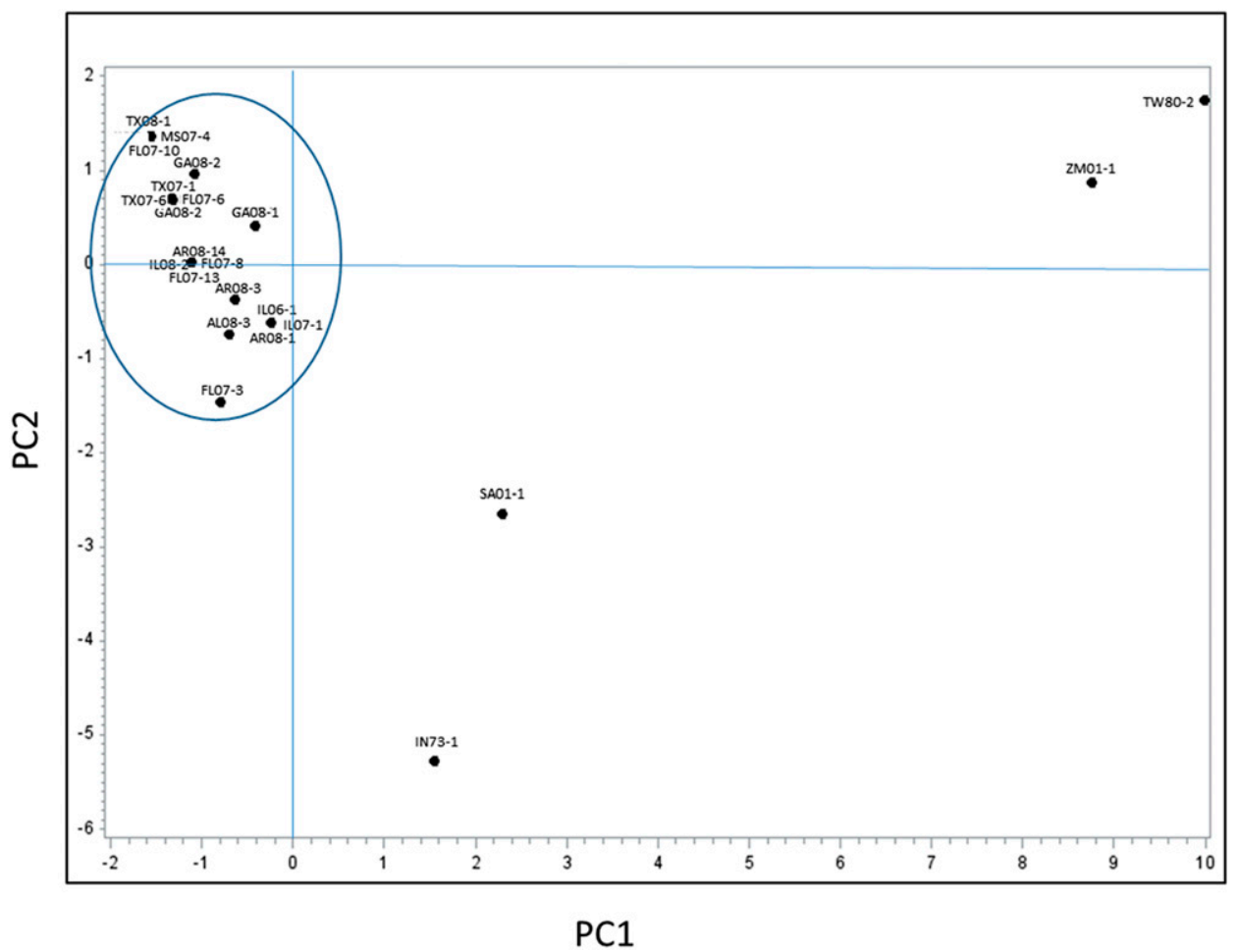

Fig. 2. Principal component analysis of reaction types on 18 soybean genotypes, including seven differential lines, after inoculation with 24 Phakopsora pachyrhizi isolates from the United States and four foreign isolates, plotted in a plane defined by the first two principal components (PC1 $\times$ PC2). The U.S. isolates are circled. 
grouped with any other isolate (Fig. 2). In a comparative analysis of the reactions induced on the $R p p 1, R p p 2, R p p 3$, and $R p p 4$ soybean genotypes by the 9 foreign isolates, 3 U.S. isolates from 2004, and 24 U.S. isolates from 2007 and 2008, PCA grouped all 24 of the more recent U.S. isolates into a single group while 4 of the foreign isolates (BZ01-1, TH01-1, PG05-1, and ZM01-1) formed another group which also included U.S. isolate AL04-1 (Fig. 3). The remaining four foreign isolates (IN73-1, SA01-1, TW80-2, and

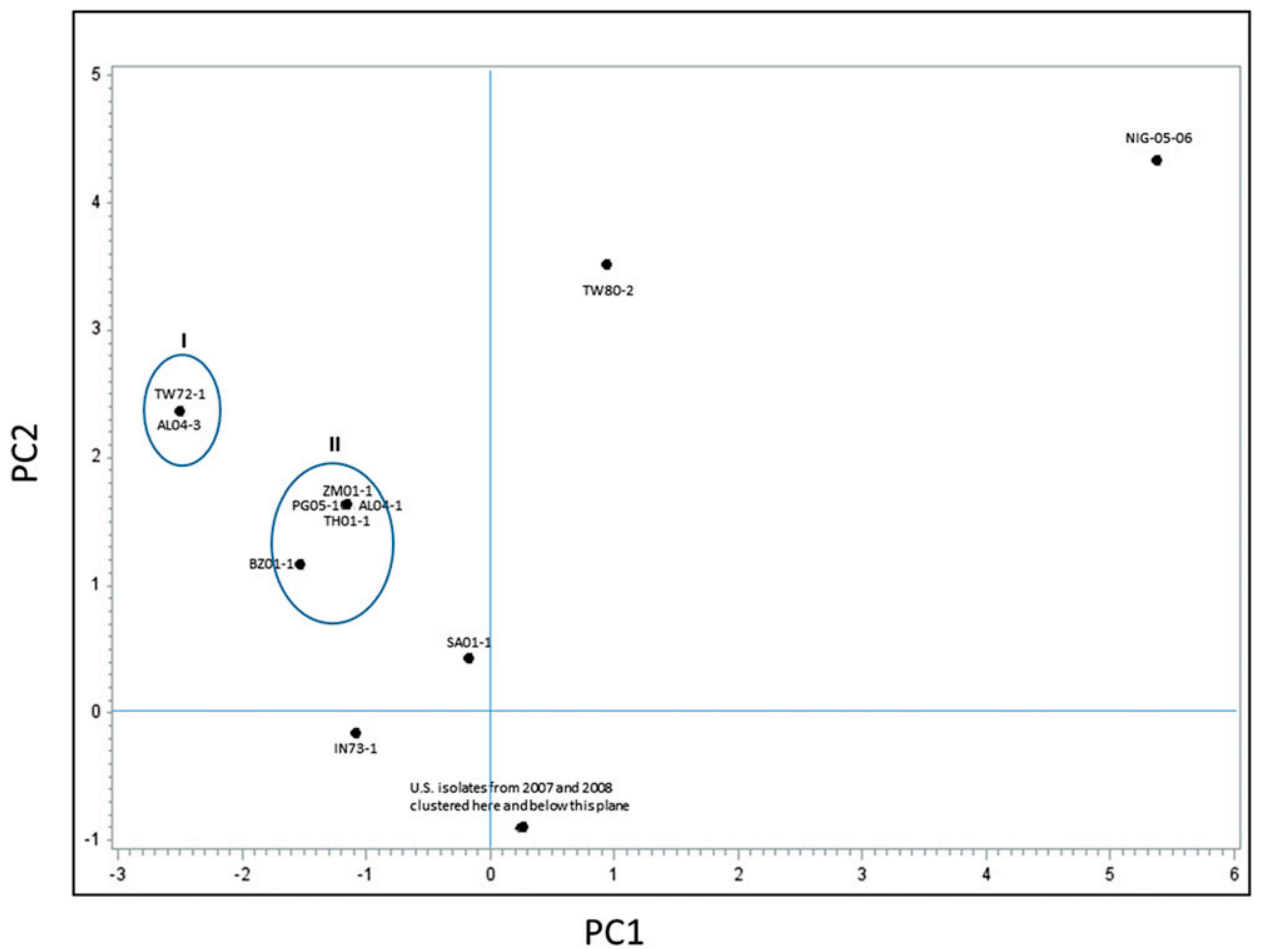

Fig. 3. Principal component analysis of reaction types on soybean Rpp1 to Rpp4 differentials after inoculation with 24 U.S. Phakopsora pachyrhizi isolates from 2007 and 2008 , 3 U.S. isolates from 2004, and 9 foreign isolates plotted in a plane defined by the first two principal components (PC1 × PC2). Group I consisted of the U.S. isolate AL04-3 and Taiwanese isolate TW72-1, and group II consisted of four foreign isolates and the U.S. isolate AL04-1.

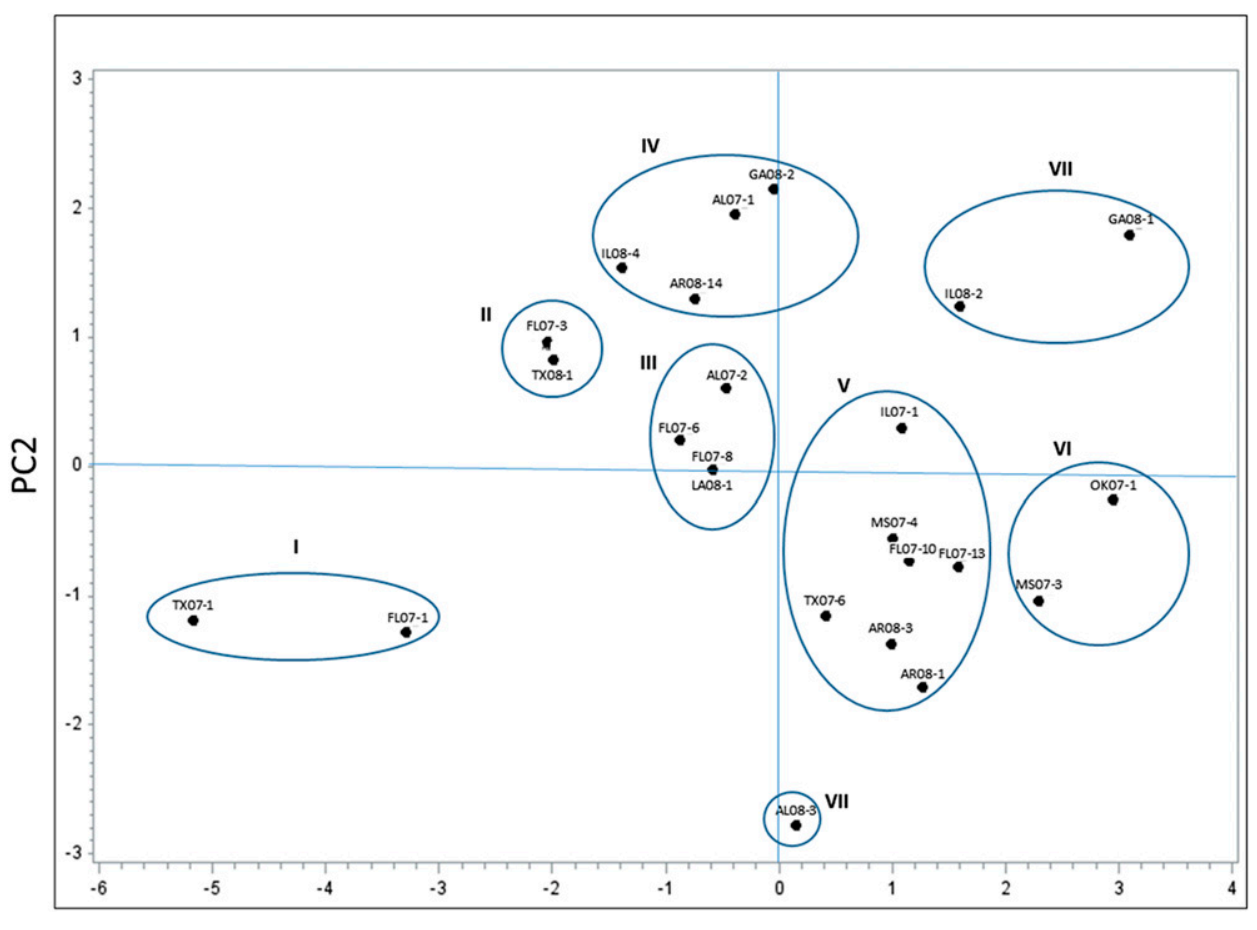

PC1

Fig. 4. Principal component and cluster analyses of disease severity after inoculation of 11 soybean differential genotypes with 24 Phakopsora pachyrhizi isolates collected in the United States in 2007 or 2008. Sample size represents the number of isolates within each cluster (circle), plotted in a plane defined by the first two principal components (PC1 $x$ PC2). Roman numerals adjacent to each cluster indicate aggressiveness aggressive groups referred to in the text. 
NG-05-06) did not group with any other isolates but TW72-1 grouped with U.S. isolate AL04-3.

Aggressiveness diversity among the U.S. $P$. pachyrhizi isolates From 2007 and 2008. Isolate-soybean genotype interactions for rust severity and uredinia density were highly significant $(P<0.001)$. PCA of rust severity ratings from 11 differential soybean genotypes grouped the 24 U.S. $P$. pachyrhizi isolates into seven aggressiveness groups (Fig. 4). The cumulative proportion of total variation for the first three PCs was $65 \%$. Large positive coefficients were revealed for PI 471904, PI 567102B, PI 462312, and UG-5, and negative coefficients for PI 594538A and Williams 82. PCA based on the densities of uredinia revealed six aggressiveness groups (Fig. 5). In the cluster analysis of the 24 U.S. isolates, the $R^{2}$ value increased steadily by 5 and $10 \%$ in the first six clusters. After six clusters, the subsequent incremental rise in the $R^{2}$ value with each additional cluster was less than $3 \%$. Thus, the optimal number of representative groups was determined using $R^{2}>5 \%$ as the cut-off point to represent the six groups of isolates. The densities of uredinia produced by the six isolate groups on the 11 differentials are summarized in Table 3. Isolates in groups I, II, and III were the most aggressive, producing significantly higher uredinial densities on most soybean genotypes than isolates in the other groups. Sporulation of isolates from all of the groups was absent or very low on the Rppl and Rpp6 genotypes and on UG-5. Based on an independent gene mapping study, UG-5 appears to have resistance genes at the Rpp1 and Rpp3 loci (unpublished data). Isolates in groups I and II were highly aggressive on PI 230970 (Rpp2), PI 462312 (Rpp3), and PI 459025B (Rpp4), despite the association of these resistance genes with the $\mathrm{RB}$ reaction type. Isolates in group VI were the least aggressive isolates.

Identification of soybean lines resistant to the 2007 and 2008 U.S. $\boldsymbol{P}$. pachyrhizi isolates. A significant $(P<0.001)$ soybean genotyperust isolate interaction was found for both rust severity and uredinia density. Isolates in aggressiveness groups established from severity data on differential soybean genotypes were used to evaluate the resistance of soybean lines (Fig. 4). Soybean lines with severity ratings $\leq 2.5$ were considered to be resistant. Groups I, II, and III contained the most aggressive isolates, and PI 567104B was the only genotype with a disease severity score $\leq 2.5$ (Table 4 ). When the average severities were summed across the seven aggressiveness groups, PI 567104B had the lowest sum, followed by PI 417089A, PI 567089A, DT2000, and PI 567046A. Seven genotypes were found to be resistant to isolates in aggressiveness group IV, while two genotypes were resistant to isolates in aggressiveness group $\mathrm{V}$.

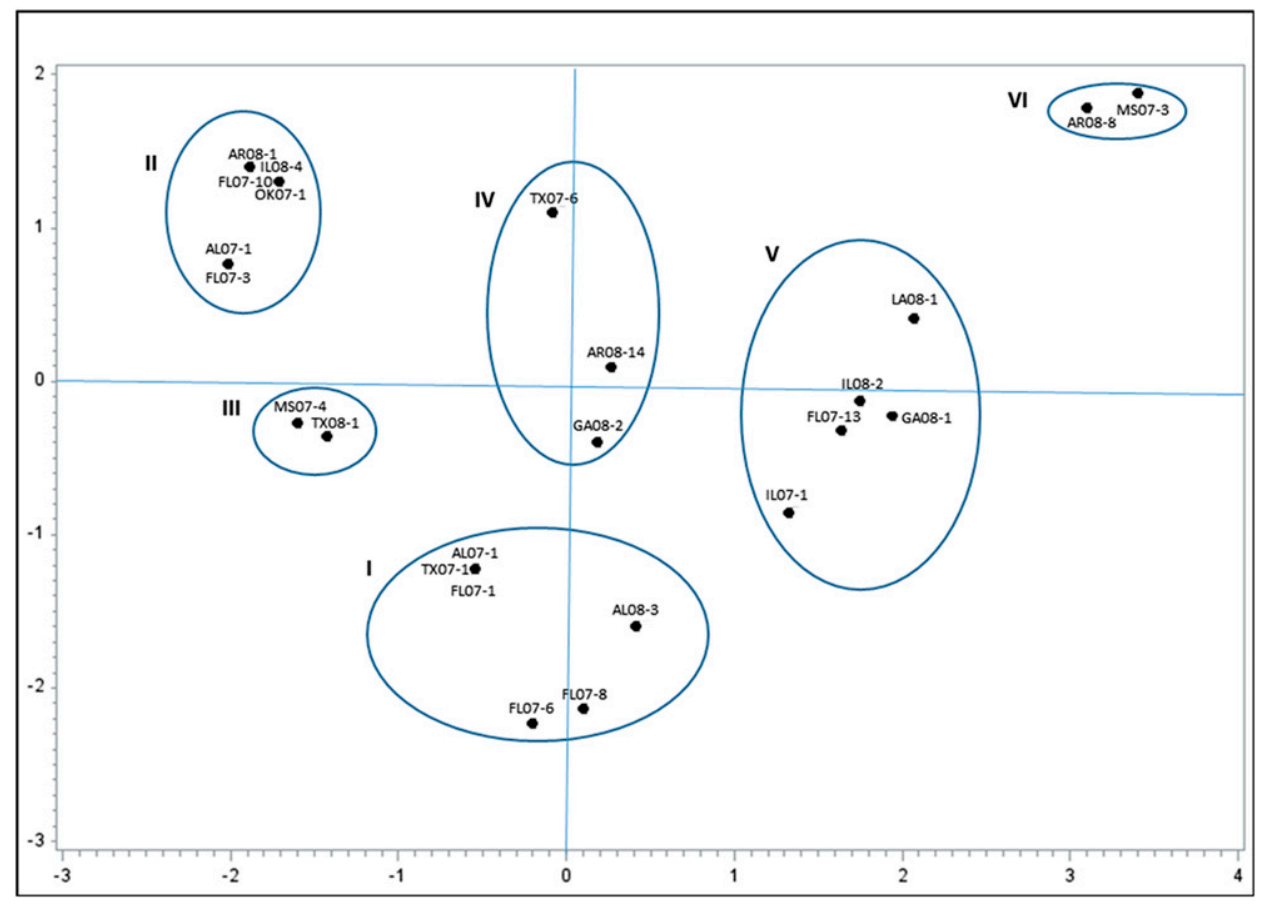

Fig. 5. Principal component and cluster analyses of number of uredinia per square centimeter after inoculation of 11 soybean differential genotypes with 24 Phakopsora pachyrhizi isolates collected in the United States in 2007 or 2008. Sample size represents the number of isolates within each group (circle), plotted in a plane defined by the first two principal components (PC1 $\times$ PC2). Roman numerals adjacent to each group indicate aggressiveness groups referred to in the text.

Table 3. Average numbers of uredinia per square centimeter on 11 soybean differentials challenged with 24 isolates of Phakopsora pachyrhizi from the United States representing six aggressiveness groups identified using cluster analysis ${ }^{\mathrm{a}}$

\begin{tabular}{|c|c|c|c|c|c|c|c|c|c|c|c|c|}
\hline Group & Isolate & $\begin{array}{c}\text { PI } 200492 \\
(\text { Rpp1) }\end{array}$ & $\begin{array}{c}\text { PI 594538A } \\
(\text { Rppl-b) }\end{array}$ & $\begin{array}{l}\text { PI 587880A } \\
\text { (Rpp1 locus) }\end{array}$ & $\begin{array}{c}\text { PI 230970 } \\
\text { (Rpp2) }\end{array}$ & $\begin{array}{c}\text { PI } 462312 \\
\text { (Rpp3) }\end{array}$ & $\begin{array}{c}\text { PI } \\
\text { 459025B } \\
\text { Rpp4 }\end{array}$ & $\begin{array}{c}\text { PI } \\
200526 \\
\text { Rpp5 }\end{array}$ & $\begin{array}{c}\text { PI } \\
471904 \\
\text { Rpp5 }\end{array}$ & $\begin{array}{c}\text { PI } \\
\text { 567102B } \\
\text { Rpp6 }\end{array}$ & UG-5 ${ }^{b}$ & $\begin{array}{c}\text { Williams } \\
82\end{array}$ \\
\hline I & 6 & 0 & $42.5(7.5)$ & $387(70)$ & $6.7(2.3)$ & $5.4(1.7)$ & $25.7(4.8)$ & $51.0(9.5)$ & $1.4(1.0)$ & $0.1(0.1)$ & 0 & $45.7(8.7)$ \\
\hline II & 6 & 0 & $0(0,5)$ & $0<(6)$ & $17.8(4.0)$ & $(3.2)$ & $25.7(4.1)$ & $36.3(5$ & $1.9(0.5)$ & $0.8(0.7)$ & 0 & $39.2(7.0)$ \\
\hline III & 2 & 0.6 & & & 13.0 & & $37.7(4.5)$ & 48.0 & 6 & 8 & 0 & $35.3(13.5)$ \\
\hline IV & 3 & & & & & & 16.8 & 19.4 & 0.1 & $0.4(0.3)$ & 0 & $19.5(3.0)$ \\
\hline V & 5 & $0.4(0.2)$ & 13.7 & $11.2(2.0)$ & 6) & $0.4(0$ & $6.6(1.6)$ & 11.4 (1.9) & $3.0(1.5)$ & 0 & $0.6(0.4)$ & $16.9(3.1)$ \\
\hline VI & 2 & 0 & $11.1(3.9)$ & $1.8(1.1)$ & $0.2(0.2)$ & $0.2(0.2)$ & $4.6(1.4)$ & $16.3(3.8)$ & $0.7(0.2)$ & 0 & 0 & $4.9(0.9)$ \\
\hline
\end{tabular}

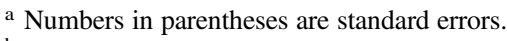

b UG-5 carries resistance alleles at the Rpp1 and Rpp3 loci (unpublished data). 
Using isolates in aggressiveness groups identified in PCA from the uredinia densities (Fig. 5), the soybean genotypes were further evaluated. PI 417089A, PI 567089A, PI 203398, and PI 567104B were resistant to the isolates in aggressiveness groups I, II, III, and IV, with uredinia densities of 0.1 to $2.5 \mathrm{uredinia} / \mathrm{cm}^{2}$ (Table 5). Soybean

Table 4. Disease severity on 21 selected soybean genotypes inoculated with 24 Phakopsora pachyrhizi isolates from the United States representing seven aggressiveness groups determined by principal component analysis

\begin{tabular}{|c|c|c|c|c|c|c|c|c|}
\hline \multirow[b]{2}{*}{ Genotypes } & \multicolumn{7}{|c|}{ Aggressiveness group $^{a}$} & \multirow{2}{*}{$\begin{array}{c}\text { Sum across } \\
\text { groups }\end{array}$} \\
\hline & $\mathbf{I}$ & II & III & IV & $\mathbf{V}$ & VI & VII & \\
\hline PI 567089A & 3.3 & 3.3 & 2.8 & 2.4 & 2.9 & 2.0 & 1.7 & 18.4 \\
\hline PI 567046A & 3.5 & 3.9 & 3.3 & 1.8 & 3.0 & 2.2 & 2.5 & 20.2 \\
\hline PI 567104B & 3.5 & 2.3 & 2.2 & 1.1 & 1.7 & 0.2 & 0.7 & 11.7 \\
\hline PI $417089 A$ & 3.7 & 3.0 & 3.0 & 1.6 & 2.4 & 2.3 & 1.2 & 17.2 \\
\hline DT 2000 & 3.8 & 3.8 & 2.7 & 2.3 & 3.0 & 2.8 & 1.7 & 20.1 \\
\hline PI 423972 & 3.8 & 4.4 & 4.0 & 3.0 & 3.3 & 2.5 & 2.3 & 23.3 \\
\hline PI 506863 & 3.8 & 4.4 & 4.3 & 4.2 & 3.9 & 2.8 & 3.3 & 26.7 \\
\hline PI $605891 \mathrm{~A}$ & 3.8 & 4.2 & 3.8 & 3.1 & 3.1 & 3.0 & 2.5 & 23.5 \\
\hline PI 203398 & 4.0 & 4.0 & 3.8 & 2.4 & 3.0 & 2.5 & 3.0 & 22.7 \\
\hline PI 398288 & 4.0 & 4.4 & 3.9 & 4.1 & 3.7 & 2.5 & 3.7 & 26.3 \\
\hline PI 224268 & 4.2 & 3.7 & 3.8 & 2.1 & 3.0 & 2.3 & 1.8 & 20.9 \\
\hline PI $587880 \mathrm{~B}$ & 4.3 & 4.2 & 4.2 & 4.2 & 3.7 & 2.8 & 2.8 & 26.2 \\
\hline PI 587886 & 4.3 & 4.2 & 3.8 & 4.1 & 3.3 & 2.8 & 2.3 & 24.8 \\
\hline PI 605779E & 4.3 & 3.9 & 4.4 & 4.1 & 3.4 & 2.8 & 2.8 & 25.7 \\
\hline PI 507305 & 4.5 & 3.6 & 4.1 & 4.0 & 3.9 & 2.7 & 4.2 & 27.0 \\
\hline PI 587905 & 4.5 & 4.4 & 3.8 & 4.6 & 3.7 & 2.8 & 3.3 & 27.1 \\
\hline PI 567351B & 4.7 & 4.9 & 4.2 & 3.6 & 3.5 & 2.7 & 2.2 & 25.8 \\
\hline PI $567041 \mathrm{~A}$ & 4.8 & 4.9 & 4.3 & 4.6 & 3.9 & 2.3 & 3.2 & 28.0 \\
\hline PI 567341 & 4.8 & 4.9 & 4.3 & 3.2 & 3.5 & 3.2 & 2.8 & 26.7 \\
\hline PI 605833 & 4.8 & 4.9 & 4.1 & 4.9 & 3.9 & 2.3 & 3.2 & 28.1 \\
\hline Williams 82 & 5.0 & 5.0 & 4.7 & 4.4 & 4.0 & 2.5 & 4.2 & 29.8 \\
\hline Isolates/cluster ( $n$ ) & 2 & 3 & 4 & 3 & 8 & 2 & 2 & $\ldots$ \\
\hline Trial mean & 4.2 & 4.1 & 3.8 & 3.3 & 3.3 & 2.5 & 2.6 & $\ldots$ \\
\hline
\end{tabular}

${ }^{\text {a }}$ Scored on a scale of 1 to 5 , where $1=$ no visible lesions, $2=$ a few scattered lesions, $3=$ a moderate number of lesions on part of the leaflet, $4=$ an abundance of lesions on part of the leaflet, and $5=$ prolific lesion development over most of the leaflet (33). Means are from three replications. Classification categories: resistant $=$ score $\leq 2.5$, moderately resistant $=$ score 2.6 to 3.0 , and susceptible $=$ score 3.1 to 5.0 . genotypes with a uredinia density $\leq 2.5$ were considered to be resistant. Cluster V isolates were highly aggressive on PI 203398, which was resistant in Paraguay (34) and in Attapulgus, GA in 2012 (53), and which had much lower uredinia densities when challenged by isolates in the other five aggressiveness groups. PI 605891A and PI $567046 \mathrm{~A}$ were similar in being highly resistant to isolates in every group except for those in group II. Eleven other genotypes were highly susceptible, with densities of 19.5 to $60.4 \mathrm{uredinia} / \mathrm{cm}^{2}$. The sums of the numbers of uredinia per square centimeter across the six aggressiveness groups reveal a 10-fold difference between the PI with the lowest density (PI 567104B) and the PIs with the highest densities (PI 506863 and PI 605833) (Table 5). Eight of the PIs had sums $<25.0$, two had sum counts between 40 and 50, and the rest of the entries, including Williams 82 , had sum counts of more than 150 .

Based on isolates in six aggressiveness groups identified from the uredinia density, nine soybean genotypes were resistant to isolates from five of the six groups as determined by the number of uredinia per lesion, with an average of 0.1 to 2.0 uredinia/lesion (Table 6). The sums of the average number of uredinia per lesion across the six aggressiveness groups indicated that PI 567104B (0.4), PI 567089A (0.5), and PI 417089A (0.5) had very high levels of resistance, though at least five other PIs had much fewer sporulating uredinia per lesion than Williams 82 (sum of 24.5) and several other genotypes.

\section{Discussion}

Knowledge of the pathogenic variation of pathogens is critical in plant breeding programs for guiding decisions about development and deployment of cultivars with genes controlling resistance to pathotypes prevalent in the target region. In this study, differences in the reaction patterns on the differential sets were considered indicative of differences in the virulence of the $P$. pachyrhizi isolates. Variation in disease severity and uredinia densities on the same host genotype was considered to reflect differences in aggressiveness, whereas different reaction types reflected the ability of an isolate to defeat resistance conditioned by a specific Rpp gene (43). Although SBR reaction type and disease severity are often correlated, there are occasional exceptions $(6,7)$.

Differences in measurements of rust traits induced on the differential set by the 24 U.S. P. pachyrhizi isolates from 2007 and 2008

Table 5. Average numbers of uredinia per square centimeter on 20 soybean genotypes and a susceptible check (Williams 82 ) challenged with 24 Phakopsora pachyrhizi isolates from the United States representing six aggressiveness groups determined by principal component and cluster analyses

\begin{tabular}{|c|c|c|c|c|c|c|c|}
\hline \multirow[b]{2}{*}{ Genotypes } & \multicolumn{6}{|c|}{ Aggressiveness group ${ }^{a}$} & \multirow[b]{2}{*}{ Sum across groups } \\
\hline & $\mathbf{I}$ & II & III & IV & $\mathbf{V}$ & VI & \\
\hline DT 2000 & $0.1(0.1)$ & $1.0(0.4)$ & $5.5(2.6)$ & $0.4(0.2)$ & $0.0(0.0)$ & $0.0(0.0)$ & 7.0 \\
\hline PI 417089A & $0.2(0.2)$ & $1.1(0.3)$ & $0.2(0.2)$ & $0.3(0.1)$ & $0.2(0.2)$ & $0.0(0.0)$ & 2.0 \\
\hline PI 605891A & $0.6(0.2)$ & $10.8(5.3)$ & $2.5(1.2)$ & $0.8(0.2)$ & $0.2(0.1)$ & $1.0(0.5)$ & 15.9 \\
\hline PI 567089A & $0.8(0.4)$ & $0.9(0.5)$ & $0.4(0.4)$ & $0.0(0.0)$ & $0.0(0.0)$ & $1.7(0.8)$ & 3.8 \\
\hline PI 203398 & $0.9(0.4)$ & $2.1(0.9)$ & $2.5(1.7)$ & $0.4(0.2)$ & $15.5(4.2)$ & $0.0(0.0)$ & 21.4 \\
\hline PI 567104B & $1.2(0.7)$ & $0.3(0.3)$ & $0.8(0.6)$ & $0.1(0.1)$ & $0.0(0.0)$ & $0.1(0.1)$ & 2.5 \\
\hline PI 567046A & $1.6(1.2)$ & $10.1(6.0)$ & $0.4(0.3)$ & $0.4(0.1)$ & $0.0(0.0)$ & $2.1(2.0)$ & 14.6 \\
\hline PI 224268 & $2.8(1.0)$ & $4.4(1.2)$ & $2.7(1.0)$ & $2.2(0.6)$ & $0.8(0.3)$ & $0.3(0.1)$ & 13.2 \\
\hline PI 423972 & $9.5(2.0)$ & $16.2(4.0)$ & $11.0(2.5)$ & $8.3(2.7)$ & $2.7(0.7)$ & $1.6(0.8)$ & 49.3 \\
\hline PI 567351B & $16.7(3.7)$ & $8.1(1.9)$ & $11.7(2.5)$ & $4.0(1.6)$ & $1.7(0.9)$ & $0.1(0.1)$ & 42.3 \\
\hline PI 567341 & $34.6(5.6)$ & $42.8(4.6)$ & $57.0(0.7)$ & $5.9(1.3)$ & $16.8(5.4)$ & $0.7(0.3)$ & 157.8 \\
\hline PI 605779E & $35.3(7.2)$ & $32.7(5.0)$ & $51.8(7.4)$ & $22.8(0.1)$ & $14.3(3.2)$ & $2.2(1.4)$ & 159.1 \\
\hline PI 587886 & $39.1(10.1)$ & $49.4(5.5)$ & $45.5(3.1)$ & $22.3(2.9)$ & $10.6(2.3)$ & $9.6(2.1)$ & 176.5 \\
\hline PI 567041A & $40.5(8.6)$ & $48.7(8.6)$ & $49.7(14.0)$ & $34.8(9.3)$ & $15.3(3.7)$ & $0.8(0.4)$ & 189.8 \\
\hline PI 587880B & $42.0(10.0)$ & $37.0(4.5)$ & $46.1(10.6)$ & $24.7(5.4)$ & $10.0(2.2)$ & $18.3(4.5)$ & 178.1 \\
\hline PI 398288 & $44.1(12.6)$ & $47.5(5.1)$ & $43.1(8.9)$ & $19.7(3.7)$ & $14.1(3.1)$ & $6.6(4.8)$ & 175.1 \\
\hline Williams 82 & $45.7(8.6)$ & $39.2(7.0)$ & $35.4(13.5)$ & $19.5(8.7)$ & $16.9(3.1)$ & $5.0(0.9)$ & 161.7 \\
\hline PI 506863 & $47.1(8.5)$ & $51.6(3.8)$ & $60.4(12.8)$ & $35.2(5.0)$ & $13.0(2.3)$ & $10.4(3.4)$ & 217.7 \\
\hline PI 605833 & $48.5(7.8)$ & $46.8(6.6)$ & $42.8(11.0)$ & $42.3(8.0)$ & $12.3(4.2)$ & $22.3(6.2)$ & 215.0 \\
\hline PI 507305 & $51.1(8.5)$ & $21.4(4.2)$ & $53.8(6.1)$ & $20.2(3.5)$ & $20.0(6.1)$ & $2.1(0.9)$ & 168.6 \\
\hline PI 587905 & $53.3(7.0)$ & $38.9(7.1)$ & $41.7(4.7)$ & $27.8(5.7)$ & $17.2(3.2)$ & $2.1(0.1)$ & 181.0 \\
\hline
\end{tabular}

a Numbers in parentheses indicate standard errors. 
indicated considerable variation for pathogenicity and aggressiveness. Despite this, PCA of reaction types revealed that the 24 isolates had a similar virulence, which differed from that of the 4 foreign SBR isolates that were tested. In contrast, the two 2004 Alabama isolates from the Pham et al. study (39) were grouped with foreign isolates, suggesting the possibility that some pathotypes that existed in the southern United States in 2004, the first growing season that SBR was found in the region, disappeared or were suppressed due to subsequent winter damage to kudzu.

Qualitative assessment of soybean reactions to SBR by classification into IM (immune), RB (resistant), or TAN (susceptible) infection types has been used in previous studies to describe virulence diversity in $P$. pachyrhizi $(39,47)$ but, within RB and TAN infection types, there are frequently quantitative differences in the number of uredinia per lesion and in the intensity of sporulation, as well as in the color of the lesions $(6,9,32,52)$. In the present study, the Rpp3 genotype PI 462312 developed nonsporulating RB lesions when challenged by all of the 2007 and 2008 U.S. isolates. PI 462312 has shown less resistance to some U.S. field populations of $P$. pachyrhizi $(47,48)$. The Rpp4 genotype PI 459025B developed an RB reaction with abundant sporulation to $25 \%$ of the 24 U.S. P. pachyrhizi isolates, and similar variation among RB or TAN infection types has been previously reported (47). PI 200492 (Rppl) developed an immune or RB infection type against all 24 of the U.S. isolates, whereas the two Alabama isolates collected in 2004 were reported to produce TAN infection types on PI 200492 and PI 462312 (Rpp3), indicating susceptibility (6,39). Avirulence genes interacting with Rpp1 and Rpp3 in the 2004 population may have been lost through genetic drift resulting from restricted survival of overwintering rust populations.

The Rpp1 and Rpp6 genes have historically been effective against $P$. pachyrhizi field populations in the southern United States $(52,53)$ and they provided high levels of resistance to the 24 domestic isolates in this study (Table 2). In 2012, however, both of these resistance genes were ineffective against a field population in north-central Florida (53) and a purified single pustule isolate established from that population (37). Interestingly, the field population at the same location was unable to defeat these two genes in 2013 (unpublished data), providing further evidence of a winter survival bottleneck. With the exception of IN73-1, the foreign isolates in the present study were virulent on Rpp1 but not on Rpp6, similar to the responses to the 2012 P. pachyrhizi population at Quincy, in northern Florida (53).
Based on the limited number of samples, the Rpp6 gene could be expected to provide broader resistance domestically and internationally than Rppl.

Based on a quantitative assessment of uredinia densities, the U.S. isolates included six aggressiveness groups, which was the same number that Twizeyimana and Hartman (47) identified among 72 U.S. isolates based on uredinia density in detached leaf assays. The 24 U.S. isolates evaluated in this greenhouse study were a subset of those 72 isolates, and our results show that pathogenic variation among the 24 U.S. isolates from 2007 and 2008 was similar to that found in the 72 isolates collected between 2006 and 2009, but different from that of the three U.S. isolates from 2004 and the foreign isolates included.

Gene-for-gene interactions in some rust fungus pathosystems have been studied using molecular and genetic analysis (4). The six aggressiveness groups described in this study represent at least part of the pathogenic diversity that existed within and among U.S. $P$. pachyrhizi field populations in 2007 and 2008, and the variation found was similar to that reported by others $(47,52)$. Altogether, the results demonstrate considerable variation in aggressiveness and virulence. Because single purified uredinial isolates from each U.S. location were used in this study, the amount of virulence diversity that existed within the P. pachyrhizi source populations is unknown; however, Twizeyimana et al. (48) found that, in Nigerian populations, $>90 \%$ of the total genetic diversity was represented within fields. The reasons why U.S. isolates in some PCA-determined groups were less virulent than isolates in others are not known, but it is possible that factors other than pathogen-soybean interactions alone were involved. For example, penetration frequencies of urediniospores have been shown to be reduced as a result of parasitism by Verticillium psalliotae and Trichothecium roseum $(27,41)$. It is also possible that natural selection on kudzu might affect virulence on soybean.

Categorization of the isolates into different aggressiveness groups on the basis of disease severity or uredinia densities revealed differential reactions between some of the 20 PIs tested in the third experiment and isolates in certain groups. Summing the data across the six or seven aggressiveness groups produced values that were useful for quick assessments of the overall resistance of each PI. Differences were particularly evident among the sums of the numbers of uredinia per square centimeter, with a 100-fold range from 2.0 to 217.7 (Table 5). PI 567104B, PI 567089A, PI 417089A, PI 567046A,

Table 6. Average numbers of uredinia per lesion on a set of 21 selected soybean genotypes produced by 24 Phakopsora pachyrhizi isolates from the United States representing six aggressiveness groups determined using principal component analysis

\begin{tabular}{|c|c|c|c|c|c|c|c|}
\hline \multirow[b]{2}{*}{ Genotypes } & \multicolumn{6}{|c|}{ Aggressiveness group ${ }^{a}$} & \multirow[b]{2}{*}{ Sum across groups } \\
\hline & $\mathbf{I}$ & II & III & IV & $\mathbf{V}$ & VI & \\
\hline DT 2000 & $0.1(0.1)$ & $0.2(0.1)$ & $0.6(0.2)$ & $0.1(0.0)$ & $0.0(0.0)$ & $0.0(0.0)$ & 1.0 \\
\hline PI 567104B & $0.1(0.1)$ & $0.2(0.2)$ & $0.1(0.1)$ & $0.0(0.0)$ & $0.0(0.0)$ & $0.0(0.0)$ & 0.4 \\
\hline PI 567046A & $0.1(0.1)$ & $0.7(0.3)$ & $0.1(0.1)$ & $0.1(0.0)$ & $0.0(0.0)$ & $0.0(0.0)$ & 1.0 \\
\hline PI 567089A & $0.1(0.1)$ & $0.1(0.1)$ & $0.1(0.1)$ & $0.0(0.0)$ & $0.0(0.0)$ & $0.2(0.1)$ & 0.5 \\
\hline PI 417089A & $0.2(0.1)$ & $0.1(0.0)$ & $0.0(0.0)$ & $0.1(0.0)$ & $0.1(0.1)$ & $0.0(0.0)$ & 0.5 \\
\hline PI 605891A & $0.2(0.1)$ & $0.7(0.3)$ & $0.4(0.2)$ & $0.2(0.0)$ & $0.1(0.1)$ & $0.5(0.2)$ & 2.1 \\
\hline PI 203398 & $0.2(0.3)$ & $0.2(0.1)$ & $0.3(0.1)$ & $0.1(0.1)$ & $2.7(0.7)$ & $0.0(0.0)$ & 3.5 \\
\hline PI 224268 & $0.5(0.1)$ & $0.6(0.2)$ & $0.5(0.2)$ & $0.7(0.2)$ & $0.5(0.2)$ & $0.0(0.0)$ & 2.8 \\
\hline PI 423972 & $1.5(0.2)$ & $2.0(0.3)$ & $1.6(0.2)$ & $1.5(0.3)$ & $1.4(0.3)$ & $1.0(0.5)$ & 9.0 \\
\hline PI 567351B & $1.5(0.3)$ & $0.6(0.1)$ & $1.2(0.1)$ & $0.7(0.2)$ & $0.5(0.1)$ & $0.0(0.0)$ & 4.5 \\
\hline Williams 82 & $4.5(0.6)$ & $4.1(0.7)$ & $5.6(1.7)$ & $3.6(0.5)$ & $4.5(0.6)$ & $2.2(0.7)$ & 24.5 \\
\hline PI 587886 & $4.6(0.4)$ & $4.8(0.6)$ & $5.4(0.3)$ & $4.0(0.6)$ & $3.6(0.7)$ & $1.5(0.2)$ & 19.3 \\
\hline PI 605779E & $4.8(0.5)$ & $3.1(2.7)$ & $8.1(0.8)$ & $3.9(0.3)$ & $4.9(0.6)$ & $0.6(0.4)$ & 25.4 \\
\hline PI 587905 & $5.1(0.3)$ & $5.1(0.7)$ & $5.7(1.0)$ & $3.7(0.6)$ & $4.5(0.7)$ & $1.1(0.6)$ & 25.2 \\
\hline PI 587880B & $5.1(0.6)$ & $3.8(0.4)$ & $5.7(1.2)$ & $3.5(0.5)$ & $3.6(1.0)$ & $2.1(0.4)$ & 16.2 \\
\hline PI 398288 & $5.2(2.6)$ & $4.5(0.6)$ & $5.3(0.9)$ & $4.0(1.0)$ & $3.3(0.7)$ & $1.3(0.9)$ & 23.6 \\
\hline PI 567341 & $5.4(0.8)$ & $3.8(0.5)$ & $5.4(0.6)$ & $1.8(0.5)$ & $4.3(0.4)$ & $0.0(0.0)$ & 20.7 \\
\hline PI 567041A & $5.4(4.1)$ & $4.2(0.5)$ & $5.2(1.4)$ & $3.4(0.5)$ & $2.5(0.4)$ & $0.6(0.4)$ & 21.3 \\
\hline PI 605833 & $5.5(0.6)$ & $5.2(0.7)$ & $4.2(0.1)$ & $5.6(0.8)$ & $2.8(0.4)$ & $4.2(0.9)$ & 27.5 \\
\hline PI 506863 & $5.6(0.5)$ & $4.9(0.7)$ & $7.3(1.0)$ & $4.7(0.5)$ & $5.0(1.2)$ & $3.4(1.4)$ & 30.9 \\
\hline PI 507305 & $6.1(3.7)$ & $2.8(0.6)$ & $9.3(2.4)$ & $3.3(0.4)$ & $3.0(0.6)$ & $0.3(0.1)$ & 24.8 \\
\hline
\end{tabular}

a Numbers in parentheses are standard errors. 
and DT 2000 all had high levels of resistance to the U.S. isolates used in this study and, therefore, would be good sources of Rpp genes in a breeding program targeting the southern United States. PI 605891A, PI 224268, PI 203398, PI 567351B, and PI 423972 developed more disease symptoms in our assays but, nevertheless, appear to have resistance genes that should also be useful in breeding for SBR resistance. Because counting uredinia per unit area using a microscope is far more time consuming than making visual assessments of disease severity in the field, it is an impractical criterion for selecting SBR-resistant plants in a breeding program. However, as can be seen in Table 4, disease severity can sometimes be quite high on resistant plants with $\mathrm{RB}$ reactions, indicating that severity data alone are not always reliable indicators of SBR resistance. Therefore, large-scale phenotypic selection of inoculated seedlings for SBR resistance should be based on a combination of disease severity and reaction type, which may sometimes be easier to rate on the basis of sporulation intensity rather than lesion color, which can change over time.

\section{Acknowledgments}

We thank the United Soybean Board for partial financial support of this research through a project entitled "Identification and Utilization of Resistance to Soybean Rust". Trade and manufacturers' names are necessary to report factually on available data; however, the USDA neither guarantees nor warrants the standard of the product, and the use of the name by USDA implies no approval of the product to the exclusion of others that may also be suitable.

\section{Literature Cited}

1. Akamatsu, H., Yamanaka, N., Yamaoka, Y., Soares, R. M., Morel, W., Ivancovich, A. J. G., Bogado, A. N., Kato, M., Yorinori, J. T., and Suenaga, K. 2013. Pathogenic diversity of soybean rust in Argentina, Brazil, and Paraguay. J. Gen. Plant Pathol. 79:28-40.

2. Bernard, R. L., and Cremeens, C. R. 1988. Registration of 'Williams 82' soybean. Crop Sci. 28:1027-1028

3. Boerma, H. R., Monteros, M. J., Ha, B.-K., Wood, E. D., Phillips, D. V., Walker, D. R., and Missaoui, A. M. 2011. Registration of Asian soybean rust-resistant soybean germplasm G01-PR16. J. Plant Regist. 5:118-122.

4. Bolton, M. D., Kolmer, J. A., and Garvin, D. F. 2008. Wheat leaf rust caused by Puccinia triticina. Mol. Plant Pathol. 9:563-573.

5. Bonde, M. R., Berner, D. K., Nester, S. E., and Frederick, R. D. 2007. Effects of temperature on urediniospore germination, germ tube growth, and initiation of infection in soybean by Phakopsora isolates. Phytopathology 97:997-1003.

6. Bonde, M. R., Nester, S. E., Austin, C. N., Stone, C. L., Frederick, R. D., Hartman, G. L., and Miles, M. R. 2006. Evaluation of virulence of Phakopsora pachyrhizi and P. meibomiae isolates. Plant Dis. 90:708-716.

7. Bonde, M. R., Nester, S. E., Berner, D. K., Frederick, R. D., Moore, W. F., and Little, S. 2008. Comparative susceptibilities of legume species to infection by Phakopsora pachyrhizi. Plant Dis. 92:30-36.

8. Bradley, C., Hines, R., Haudenshield, J. S., and Hartman, G. L. 2010. First report of soybean rust, caused by Phakopsora pachyrhizi, on kudzu (Pueraria montana var. lobata) in Illinois. Plant Dis. 94:477.

9. Bromfield, K. R. 1984. Soybean Rust, Monograph No. 11. American Phytopathological Society, St. Paul, MN.

10. Bromfield, K. R., and Hartwig, E. E. 1980. Resistance to soybean rust and mode of inheritance. Crop Sci. 20:254-255.

11. Burdon, J. J., and Silk, J. 1997. Sources and patterns of diversity in plantpathogenic fungi. Phytopathology 87:664-669.

12. Chakraborty, N., Curley, J., Frederick, R. D., Hyten, D. L., Nelson, R. L., Hartman, G. L., and Diers, B. W. 2009. Mapping and confirmation of a new allele at Rppl from soybean PI 594538A conferring RB-type resistance to soybean rust. Crop Sci. 49:783-790.

13. Chakraborty, S., Obanor, F., Westecott, R., and Abeywickrama, K. 2010. Wheat crown rot pathogens Fusarium graminearum and $F$. pseudograminearum lack specialization. Phytopathology 100:1057-1065.

14. Cherry, E., and Peet, C. E. 1966. An efficient device for the rapid collection of fungal spores from infected plants. Phytopathology 56:1102-1103.

15. Diers, B. W., Kim, K.-S., Frederick, R. D., Hartman, G. L., Unfried, J., Schultz, S., and Cary, T. 2014. Registration of eight soybean germplasm lines resistant to soybean rust. J. Plant Regist. 8:96-101.

16. Garcia, A., Calvo, E. S., de Souza Kiihl, R. A., Harada, A., Hiromoto, D. M., and Viera, L. G. E. 2008. Molecular mapping of soybean rust (Phakopsora pachyrhizi) resistance genes: Discovery of a novel locus and alleles. Theor. Appl. Genet. 117:545-553.

17. Godoy, C. V. 2009. Changes in performance of soybean rust fungicides over years and new management strategies adopted in Brazil. In: Natl. Soybean Rust Symp. New Orleans, LA. http://www.plantmanagementnetwork.org/ infocenter/topic/soybeanrust/2009/presentations/Godoy.pdf

18. Godoy, C. V. 2012. Risk and management of fungicide resistance in the Asian soybean rust fungus Phakopsora pachyrhizi. In: Fungicide Resistance in Crop
Protection: Risk and Management. T. S. Thind, ed. CAB International, Wallingford, UK.

19. Hartwig, E. E. 1986. Identification of a fourth major gene conferring resistance to soybean rust. Crop Sci. 26:1135-1136.

20. Hartwig, E. E., and Bromfield, K. R. 1983. Relationship among three genes conferring specific resistance to rust in soybeans. Crop Sci. 23:237-239.

21. Hyten, D. L., Hartman, G. L., Nelson, R. L., Frederick, R. D., Concibido, V. C., Narvel, J. M. and Cregan, P. B. 2007. Map location of the Rppl locus that confers resistance to soybean rust in soybean. Crop Sci. 47:837-840.

22. Hyten, D. L., Smith, J. R., Frederick, R. D., Tucker, M. L., Song, Q., and Cregan, P. 2009. Bulked segregant analysis using the Goldengate assay to locate the Rpp3 locus that confers resistance to soybean rust in soybean. Crop Sci. 49:265-271.

23. Jordan, S. A., Mailhot, D. J., Gevens, A. J., Marois, J. J., Wright, D. L., Harmon, C. L., and Harmon, P. F. 2010. Characterization of kudzu (Pueraria spp.) resistance to Phakopsora pachyrhizi, the causal agent of soybean rust. Phytopathology 100:941-948.

24. Kawuki, E., Adipala, E., and Tukamuhabwa, P. J. 2003. Yield loss associated with soybean rust (Phakopsora pachyrhizi Syd.) in Uganda. Phytopathology 151:7-12.

25. Kendrick, M. D., Harris, D. K., Ha, B.-K., Hyten, D. L., Cregan, P. B., Frederick, R. D., Boerma, H. R., and Pedley, K. F. 2011. Identification of a second Asian soybean rust resistance gene in Hyuuga soybean. Phytopathology 101:535-543.

26. Kingsolver, C. H., Melching, J. S., and Bromfield, K. R. 1983. The threat of exotic plant pathogens to agriculture in the United States. Plant Dis. 67: 595-600.

27. Kumar, S., and Jha, D. K. 2002. Trichothecium roseum: A potential agent for the biological Control of soybean rust. Indian Phytopathol. 55:232-234.

28. Levy, C. 2005. Epidemiology and chemical control of soybean rust in Southern Africa. Plant Dis. 89:669-674.

29. Li, S., Smith, J. R., Ray, J. D., and Frederick, R. D. 2012. Identification of a new soybean rust resistance gene in PI 567102B. Theor. Appl. Genet 125:133-142.

30. Livingston, M., Johanson, R., Daberkow, S., Robets, M., Ash, M., and Breneman, V. 2004. Economic and policy implications of wind-borne entry of Asian soybean rust into the United States. Online publication. U. S. Dep. Agric. Econ. Res. Serv. Electron. Outlook Rep. No. OCS-04D-02. http:// naldc.nal.usda.gov/download/34153/PDF

31. McLean, R. J., and Byth, D. E. 1980. Inheritance of resistance to rust (Phakopsora pachyrhizi) in soybeans. Aust. J. Agric. Res. 31:951-956.

32. Miles, M. R., Bonde, M. R., Nester, S. E., Berner, D. K., Frederick, R. D., and Hartman, G. L. 2011. Characterizing resistance to Phakopsora pachyrhizi in soybean. Plant Dis. 95:577-581.

33. Miles, M. R., Frederick, R. D., and Hartman, G. L. 2006. Evaluation of soybean germplasm for resistance to Phakopsora pachyrhizi. Online publication. Plant Health Prog.

34. Miles, M. R., Morel, W., Ray, J. D., Smith, J. R., Frederick, R. D., and Hartman, G. L. 2008. Adult plant evaluation of soybean accessions for resistance to Phakopsora pachyrhizi in the field and greenhouse in Paraguay. Plant Dis. 92:96-105.

35. Ono, Y., Buritica, P., and Hennen, J. F. 1992. Delimitation of Phakopsora, Physopella and Cerotelium and their species on Leguminosae. Mycol. Res. 96:825-50.

36. Paul, C., and Hartman, G. L. 2009. Sources of soybean rust resistance challenged with single-spored isolates of Phakopsora pachyrhizi. Crop Sci. 49:1781-1785.

37. Paul, C., Hartman, G. L., Marois, J. J., Wright, D. L., and. Walker, D. R. 2013. First report of Phakopsora pachyrhizi overcoming soybean genotypes with Rppl or Rpp6 rust resistance genes in field plots in the United States. Plant Dis. 97:1379.

38. Paul, C., Hill, C. B., and Hartman, G. L. 2011. Comparisons of visual rust assessments and DNA levels of Phakopsora pachyrhizi in soybean genotypes varying in rust resistance. Plant Dis. 95:1007-1012.

39. Pham, T. A., Miles, M. R., Frederick, R. D., Hill, C. B., and Hartman, G. L. 2009. Differential responses of resistant soybean entries to isolates of Phakopsora pachyrhizi. Plant Dis. 93:224-228.

40. Ray, J. D., Morel, W., Smith, J. R., Frederick, R. D., and Miles, M. R. 2009 Genetics and mapping of adult plant rust resistance in soybean PI 587886 and PI 587880A. Theor. Appl. Genet. 119:271-280.

41. Saksirirat, W., and Hopp, H. H. 1990. Light and scanning electron microscopic studies on the development of the mycoparasite Verticillium psalliotae Treschow on uredospores of the soybean rust (Phakopsora pachyrhizi Syd.). J. Phytopathol. 128:340-344

42. Schneider, R. W., Hollier, C. A., Whitam, H. K., Palm, M. E., McKemy, J. M., Hernández, J. R., Levy, L., and DeVries-Paterson, R. 2005. First report of soybean rust caused by Phakopsora pachyrhizi in the continental United States. Plant Dis. 89:774.

43. Shaner, G., Stromberg, E. L., Lacy, G. H., Barker, K. R., and Pirone, T. P. 1992. Nomenclature and concepts of pathogenicity and virulence. Annu. Rev. Phytopathol. 30:47-66.

44. Sharma, R., Upadhyaya, H. D., Manjunatha, S. V., Rai, K. N., Gupta, S. K. and Thakur, R. P. 2013. Pathogenic variation in the pearl millet blast 
pathogen Magnaporthe grisea and identification of resistance to diverse pathotypes. Plant Dis. 97:189-195.

45. Sikora, E. J., Delaney, D. P., Delaney, M. A., Lawrence, K. S., and Peques, M. 2009. Evaluation of sequential fungicide spray programs for control of soybean rust. Online publication. Plant Health Prog.

46. Silva, D. D. G., Yamanaka, N., Brogin, R. I., Arias, C. A. A., Nepomuceno, A. L., Di Mauro, A. O., Pereira, S. S., Nogueira, L. M., Passianotto, A. L. L., and Abdelnoor, R. V. 2008. Molecular mapping of two loci that confer resistance to Asian rust in soybean. Theor. Appl. Genet. 117:57-63.

47. Twizeyimana, M., and Hartman, G. L. 2012. Pathogenic variation of Phakopsora pachyrhizi isolates on soybean in the United States from 2006 to 2009. Plant Dis. 96:75-81.

48. Twizeyimana, M., Ojiambo, P. S., Haudenshield, J. S., Caetano-Anolles, G., Pedley, K. F., Bandyopadhyay, R., and Hartman, G. L. 2011. Genetic structure and diversity of Phakopsora pachyrhizi isolates from soyabean. Plant Pathol. 60:719-729.

49. Twizeyimana, M., Ojiambo, P. S., Ikotun, T., Paul, C., Hartman, G. L., and Bandyopadhyay, R. 2007. Comparison of field, greenhouse, and detachedleaf evaluations of soybean germplasm for resistance to Phakopsora pachyrhizi. Plant Dis. 91:1161-1169.

50. Twizeyimana, M., Ojiambo, P. S., Sonder, K., Ikotun, T., Hartman, G. L., and Bandyopadhyay, R. 2009. Pathogenic variation of Phakopsora pachyrhizi infecting soybean in Nigeria. Phytopathology 99:353-361.

51. Vittal, R., Yang, H.-C., and Hartman, G. L. 2012. Anastomosis of germ tubes and nuclear migration of nuclei in germ tube networks of the soybean rust pathogen, Phakopsora pachyrhizi. Eur. J. Plant Pathol. 132:163-167.
52. Walker, D. R., Boerma, H. R., Phillips, D. V., Schneider, R. W., Buckley, J. B., Shipe, E. R., Mueller, J. D., Weaver, D. B., Sikora, E. J., Moore, S. H., Hartman, G. L., Miles, M. R., Harris, D. K., Wright, D. L., Marois, J. J., and Nelson, R. L. 2011. Evaluation of USDA soybean germplasm accessions for resistance to soybean rust in the southern United States. Crop Sci. 51:678-693.

53. Walker, D. R., Harris, D. K., King, Z. R., Li, Z., Boerma, H. R., Buckley, J. B., Weaver, D. B., Sikora, E. J., Shipe, E. R., Mueller, J. D., Buck, J. W., Schneider, R. W., Marois, J. J., Wright, D. L., and Nelson, R. L. 2014 Evaluation of soybean germplasm accessions for resistance to Phakopsora pachyrhizi populations in the southeastern United States, 2009-2012. Crop Sci. 54:1673-1689.

54. Yamanaka, N., Yamaoka, Y., Kato, M., Lemos, N. G., Passianotto, A., Santos, J., Benitez, E., Abdelnoor, R., Soares, R., and Suenaga, K. 2010. Development of classification criteria for resistance to soybean rust and differences in virulence among Japanese and Brazilian rust populations. Trop. Plant Pathol. 35:153-162.

55. Yamaoka, Y., Yamanaka, N., Akamatsu, H., and Suenaga, K. 2014 Pathogenic races of soybean rust Phakopsora pachyrhizi collected in Tsukuba and vicinity in Ibaraki, Japan. J. Gen. Plant Pathol. 80:184-188.

56. Yeh, C. C. 1983. Physiological races of Phakopsora pachyrhizi in Taiwan. J. Agric. Res. China 32:69-74

57. Yorinori, J. T., Paiva, W. M., Frederick, R. D., Costamilan, L. M., Bertagnolli, P. F., Hartman, G. L., Godoy, C. V., and Nunes, J., Jr. 2005. Epidemics of soybean rust (Phakopsora pachyrhizi) in Brazil and Paraguay from 20012003. Plant Dis. 89:675-677. 